\title{
Produção e renda bruta da calêndula, alface e rabanete solteiros e consorciados com dois arranjos de plantas
}

\section{Yield and gross income of marigold, lettuce and radish in monocrop and intercropped with two arrangements of plants}

\author{
Inez Aparecida de Oliveira Pelloso ${ }^{1}$; Maria do Carmo Vieira ${ }^{2 *}$; \\ Néstor Antonio Heredia Zárate ${ }^{3}$; Maria Carmo dos Santos ${ }^{4}$
}

\begin{abstract}
Resumo
O consórcio de plantas se apresenta como um dos métodos mais adequados à prática da olericultura em moldes agroecológicos, com inúmeras vantagens no aspecto ambiental, produtivo e econômico. $\mathrm{O}$ objetivo deste trabalho foi avaliar as produtividades e as rendas brutas da calêndula, alface e rabanete cultivados solteiros e consorciados, sob dois arranjos de plantas. A calêndula 'Bonina', a alface 'Verônica' e o rabanete 'Crimson Vip-R foram alocados no campo em experimento conjunto. A calêndula foi estudada como fatorial 2 (solteiro e consorciado) x 2 (duas e três fileiras de plantas no canteiro) +2 (consorciado com alface e consorciado com rabanete). A alface e o rabanete foram estudados como fatorial 2 (solteiros e consorciados com calêndula) x 2 (três e quatro fileiras de plantas no canteiro). Os dez tratamentos foram arranjados no delineamento experimental blocos casualizados, com quatro repetições. Os dados obtidos foram analisados por espécie. A calêndula cultivada com três fileiras produziu maiores número $\left(4.250,75 \mathrm{mil} \mathrm{ha}^{-1}\right)$ e massas fresca $\left(7.578,00 \mathrm{~kg} \mathrm{ha}^{-1}\right)$ e seca $(928,09$ $\mathrm{kg} \mathrm{ha}^{-1}$ ) de capítulos florais. A calêndula consorciada com alface produziu 5.786,25 e 631,03 $\mathrm{kg} \mathrm{ha}^{-1} \mathrm{de}$ massas frescas e secas de capítulos florais, independente do número de fileiras. A maior massa fresca das cabeças comerciais de alface $\left(7.783,33 \mathrm{~kg} \mathrm{ha}^{-1}\right)$ foi no cultivo solteiro. A maior produção de rabanete $\left(3.700,25 \mathrm{~kg} \mathrm{ha}^{-1}\right)$ foi no consórcio calêndula três fileiras e rabanete quatro fileiras. Considerando a razão de área equivalente e a renda bruta, os consórcios foram melhores que os cultivos solteiros. Para os produtores de calêndula e de alface recomenda-se o consórcio calêndula com duas fileiras e alface com três fileiras e para o produtor de rabanete, recomenda-se o consórcio calêndula com duas fileiras e rabanete com três fileiras, para que obtenham maior renda bruta.
\end{abstract}

Palavras-chave: Calendula officinalis, Lactuca sativa, Raphanus sativus, sistema de cultivo, arranjo de plantas

\begin{abstract}
The intercropping of plants presents itself as one of most appropriate methods to the olericulture in agroecological molds, with several advantages in the environment, productive and economic aspects. The aim of this work was to evaluate the yield and gross income of marigold, lettuce and radish grown
\end{abstract}

\footnotetext{
${ }^{1}$ Eng $^{\mathrm{a}}$ Agr ${ }^{\mathrm{a}}$, Pós-graduanda do curso de Doutorado em Agronomia, Universidade Federal da Grande Dourados, Faculdade de Ciências Agrárias, UFGD, C. P. 533, 79804-970, Dourados, MS. E-mail: iapelloso@hotmail.com

${ }^{2}$ Prof. Titular e Bolsista de Produtividade em Pesquisa do CNPq, UFGD, C. P. 533, 79804-970, Dourados, MS. E-mail: vieiracm@, terra.com.br

${ }^{3}$ Prof. Associado III e Bolsista de Produtividade em Pesquisa do CNPq, UFGD, C. P. 533, 79804-970, Dourados, MS. E-mail: nahz (a)terra.com.br

${ }^{4}$ Bacharel em Ciências Biológicas, Pós-graduanda do curso de Mestrado em Agronomia, UFGD, C. P. 533, 79804-970, Dourados, MS. E-mail: mariasato@ibest.com.br

* Autor para correspondência
} 
in monocrop and intercropped, in two arrangements of plants. The marigold 'Bonina', the lettuce 'Verônica' and the radish 'Crimson Vip-R' were allocated in the field in an experiment set. Marigold was studied as factorial 2 (monocrop and intercropping) $\mathrm{x} 2$ (two and three rows of plants per plot) +2 (intercropped with lettuce and intercropped with radish). Lettuce and radish were studied as factorial 2 (monocrop and intercropping with marigold) $\mathrm{x} 2$ (three and four rows of plants per plot). Ten treatments were arranged in randomized block with four repetitions. The values obtained were analyzed by specie. There was significant interaction between cropping systems and plant arrangement for the number and fresh and dry weight of marigold capitula's. Marigold grown with three rows produced greater number $\left(4,250.75 \mathrm{mil} \mathrm{ha}^{-1}\right)$ and fresh weight $\left(7,578.00 \mathrm{~kg} \mathrm{ha}^{-1}\right)$ and dry $\left(928.09 \mathrm{~kg} \mathrm{ha}^{-1}\right)$ of marigold capitula's intercropped with lettuce produced 5,786.25 and $631.03 \mathrm{~kg} \mathrm{ha}^{-1}$ of fresh and dry weight of capitula, regardless of the number of rows. The highest fresh weight of commercial heads of lettuce $\left(7,783.33 \mathrm{~kg} \mathrm{ha}^{-1}\right)$ was obtained in the monocrop. The highest yield of radish $\left(3,700.25 \mathrm{~kg} \mathrm{ha}^{-1}\right)$ was in the intercropping between marigold three rows and radish four rows. Considering the Land Equivalent Ratio (LER) and gross income, it was concluded that the intercropping was better option than monocrop. For the marigold and lettuce producers is recommended the intercropping marigold with two rows and lettuce with three rows and for the radish producer is recommended the intercropping marigold with two rows and radish with three rows, to obtain highest gross income.

Key words: Calendula officinalis, Lactuca sativa, Raphanus sativus, cropping system, plant arrangement

\section{Introdução}

A calêndula (Calendula officinalis L.) é uma planta européia aclimatada no Brasil, herbácea, de ciclo anual ou bianual em climas temperados. É extensamente utilizada pelas indústrias farmacêutica, cosmética e alimentícia e pela população em geral, por causa das suas atividades terapêuticas e para fins ornamentais. As plantas contêm, entre outros, ácido salicílico, ácido fenólico, carotenóides, óleo essencial, saponinas, resina, minerais, flavonóides e triterpenos, com importantes princípios antiinflamatórios (BAUMANN, 2003). A inflorescência é a parte da planta mais utilizada, da qual se extraem óleos essenciais e pigmentos, utilizados em diversos medicamentos (FROMENT; MASTEBROEK; GORP, 2005). O óleo extraído de suas sementes contém em torno de $60 \%$ de ácido calêndico, o qual pode ter aplicações na fabricação de tintas e produtos industriais de fibra sintética (CROMACK; SMITH, 1998).

Dentre as atividades farmacológicas da calêndula cita-se a ação bactericida contra Staphylococcus aureus e Staphylococcus fecalis, como estimulante da atividade hepática, na secreção biliar e no tratamento de úlceras gástricas (GIL et al., 2000). Também têm sido reportadas atividades imunomodulatória (AMIRGHOFRAN;
AZADBAKHT; KARIMI, 2000); antitumoral (ELIAS et al., 1990); antimutagênica e antiviral (GRUENWALD; BRENDLER; JAENICKE, 2000); antimicrobiana (HSIEH; MAU; HUANG, 2001) e como moluscicida (HELALY; AHMED; ELGHAFFAR, 1999). O óleo essencial é utilizado como nematicida (PEREZ et al., 2003) e larvicida (ELSHAZLY; HUSSEIN, 2004). Estudos sugerem que extratos orgânicos das flores possuem propriedades terapêuticas anti-HIV (KALVATCHEV; WALDER; GARZARO, 1997).

Nas indústrias de perfumes há aproximadamente 200 formulações constituintes de extratos de Calendula officinalis que entram na fabricação de cosméticos, devido aos diversos princípios ativos da planta que são responsáveis pelos eficientes efeitos no tratamento de pele e cabelos (BAUMANN, 2003). O aroma característico das flores de calêndula é associado à presença dos sesquiterpenos na fração volátil, dentre esses o d-cadineno que confere as notas verdes, doces e refrescantes; e o a-cadinol responsável pelas notas amadeiradas (REZNICEK; ZITTERL-EHLSEER, 2003).

Para o cultivo de calêndula, vários autores (LUZ; FERRADA; GOVIN, 2001; MARTINS et al., 2000; SARTÓRIO et al., 2000) recomendam espaçamentos entre plantas de 20 a $35 \mathrm{~cm}$ e entre 
fileiras de 30 a $50 \mathrm{~cm}$. Crnobarac et al. (2008), em experimento com quatro variedades de calêndula (Bački Petrovac, Orange King, Plamen e Plamen Plus) e quatro espaçamentos entre plantas (40, 50, 60 e $70 \mathrm{~cm}$ ), obtiveram maior rendimento médio da massa fresca de capítulos florais da calêndula (6.427 $\mathrm{kg} \mathrm{ha}^{-1}$ ) sob o espaçamento de $40 \mathrm{~cm}$ entre plantas. Gomes, Vieira e Heredia Zárate (2007), avaliando a produção da calêndula em função das densidades 60.000, 80.000, 100.000 e 120.000 plantas ha ${ }^{-1}$ e dos arranjos de plantas três e quatro fileiras por canteiro $(36,0 \mathrm{~cm}$ e $27,0 \mathrm{~cm}$ entre fileiras, respectivamente) correspondentes, respectivamente, aos espaçamentos entre plantas de 33,0;24,7; 19,8 , 16,5 cm e 44,0;33,0;26,5 e 22,0 cm, concluíram que as maiores massa fresca $\left(4.860,9 \mathrm{~kg} \mathrm{ha}^{-1}\right)$ e seca $\left(862,59 \mathrm{~kg} \mathrm{ha}^{-1}\right)$ dos capítulos florais foram quando utilizou-se densidade de 120.000 plantas ha-1 e três fileiras de plantas no canteiro.

Quanto à alface (Lactuca sativa L.), é a hortaliça folhosa de maior importância no Brasil com uma área cultivada de 35.000 ha. A planta tem ciclo curto (60 a 80 dias) e, pela escolha criteriosa das cultivares disponíveis, é possível colher as "cabeças", de boa qualidade, ao longo do ano todo (FILGUEIRA, 2008). Seu cultivo é feito de maneira intensiva e geralmente praticada pela agricultura familiar, sendo responsável pela geração de cinco empregos diretos por hectare (COSTA; SALA, 2005). Uma das maneiras de produzi-la é através do uso da prática da consorciação de culturas (BEZERRA NETO et al., 2003; OLIVEIRA et al., 2004; FREITAS et al., 2004). Segundo Camargo (1992), a alface é uma excelente fonte de vitamina $\mathrm{A}$, possuindo ainda as vitaminas $\mathrm{B}_{1}, \mathrm{~B}_{2}, \mathrm{~B}_{5}$ e $\mathrm{C}$, além dos minerais $\mathrm{Ca}, \mathrm{Fe}$, $\mathrm{Mg}, \mathrm{P}, \mathrm{K}$ e Na, cujos teores variam de acordo com a cultivar.

Em relação ao rabanete (Raphanus sativus L.), a planta tem porte reduzido e, nas cultivares de maior aceitação, produz raízes globulares, de coloração escarlate-brilhante e polpa branca (FILGUEIRA, 2008). O rabanete apresenta diversas propriedades, atuando como diurético, antiescorbútico, estimulante das glândulas digestivas, estimulante do fígado (MINAMI; TESSARIOLI NETTO, 1994). Além disso, é uma ótima fonte de cálcio, fósforo, ferro e manganês, contendo, ainda, vitaminas $\mathrm{B}_{1}$ e $\mathrm{B}_{2}$, ácido nicotínico e vitamina C (MINAMI; TESSARIOLI NETTO, 1997). No Brasil, o rabanete não é considerado atualmente, como uma cultura de muita expressão em termos de área cultivada e produção. Contudo, é uma cultura de elevada rentabilidade (CECÍLIO FILHO; MAY, 2002), especialmente por ser de ciclo curto e, por isso, propiciar rápido giro de capital. Pode ser usado como cultura intercalar entre outras de ciclo mais longo, permitindo a composição de sistemas consorciados.

O consórcio de plantas se apresenta como um dos métodos mais adequados à prática da olericultura em moldes agroecológicos, com inúmeras vantagens no aspecto ambiental, produtivo e econômico, devido, dentre outros, à maior eficiência de utilização da terra, melhor uso dos recursos ambientais, eficiência no controle da erosão e controle de plantas daninhas. Além disso, serve para a diminuição dos riscos de perdas totais, diversificação da dieta alimentar do trabalhador rural e possibilidade de obtenção de maiores fontes de renda (SULLIVAN, 2003).

O consórcio de uma planta medicinal com hortaliças torna-se promissor para as pequenas propriedades que utilizam mão-de-obra familiar, para o aumento da produtividade por unidade de área e para produção diversificada de alimentos. Nenhum trabalho foi encontrado na literatura consultada sobre a consorciação de calêndula, por isso, o objetivo deste trabalho foi avaliar as produtividades e as rendas brutas da calêndula, alface e rabanete cultivados solteiros e consorciados, sob dois arranjos de plantas.

\section{Material e Métodos}

O experimento foi desenvolvido no Horto de Plantas Medicinais - HPM, da Universidade Federal da Grande Dourados - UFGD, em Dourados-MS, de junho a novembro de 2009. O HPM situa-se em 
latitude de $22^{\circ} 11^{\prime} 43^{\prime \prime} \mathrm{S}$, longitude de 54'56'08'W e altitude de $458 \mathrm{~m}$. O clima da região, segundo a classificação de Köppen, é Mesotérmico Úmido; do tipo Cwa, com temperaturas e precipitações médias anuais variando de $20^{\circ}$ a $24^{\circ} \mathrm{C}$ e de $1250 \mathrm{~mm}$ a 1500 $\mathrm{mm}$, respectivamente.

O solo da área experimental é classificado como Latossolo Vermelho Distroférrico, de textura muito argilosa. As características químicas do solo foram de 5,9 de pH em água $(1: 2,5) ; 4,9 ; 4,1 ; 14,0$ e 29,0 $\mathrm{mmol}_{\mathrm{c}} \mathrm{dm}^{-3}$ de $\mathrm{Al}^{+3}, \mathrm{~K}, \mathrm{Mg}$ e Ca; 30,0 $\mathrm{mg} \mathrm{dm}^{-3}$ de P; 47,1 $\mathrm{mmol}_{\mathrm{c}} \mathrm{dm}^{-3}$ de soma de bases; 109,1 $\mathrm{mmol}_{\mathrm{c}}$ $\mathrm{dm}^{-3}$ de capacidade de troca de cátions; $43,0 \%$ de saturação por bases e $25,9 \mathrm{~g} \mathrm{~kg}^{-1}$ de matéria orgânica.

A calêndula 'Bonina', a alface 'Verônica' e o rabanete 'Crimson Vip-R' foram alocados no campo em experimento conjunto (HEREDIA ZÁRATE et al., 2006b). A calêndula foi estudada como fatorial 2 (solteiro e consorciado) x 2 (duas e três fileiras de plantas no canteiro) +2 (consorciado com alface e consorciado com rabanete). A alface e o rabanete foram estudados como fatorial 2 (solteiros e consorciados com calêndula) x 2 (três e quatro fileiras de plantas no canteiro) (Figura 1). Dessa forma, o total foi de dez tratamentos, que foram arranjados no delineamento experimental blocos casualizados, com quatro repetições. Cada parcela tinha área total de 3,6 m² (1,5 m de largura x 2,4 $\mathrm{m}$ de comprimento) e área útil de $2,59 \mathrm{~m}^{2}$ (1,08 m de largura do canteiro x 2,4 m de comprimento). Para calêndula, os espaçamentos entre fileiras nos cultivos solteiros e consorciados foram de $0,50 \mathrm{~m}$ e $0,33 \mathrm{~m}$; para alface e rabanete foram de $0,25 \mathrm{~m} \mathrm{e}$ $0,33 \mathrm{~m}$ para quatro e três fileiras, respectivamente. Os espaçamentos entre plantas na fileira, tanto no cultivo solteiro quanto no consorciado, foram de $0,30 \mathrm{~m}$ para calêndula e alface e de $0,05 \mathrm{~m}$ para rabanete.

Figura 1. Arranjo de plantas de Calêndula 'Bonina', com duas e três fileiras de plantas e de alface 'Verônica' ou o rabanete 'Crimson Vip-R', com três e quatro fileiras de plantas, como culturas solteiras e consorciadas.

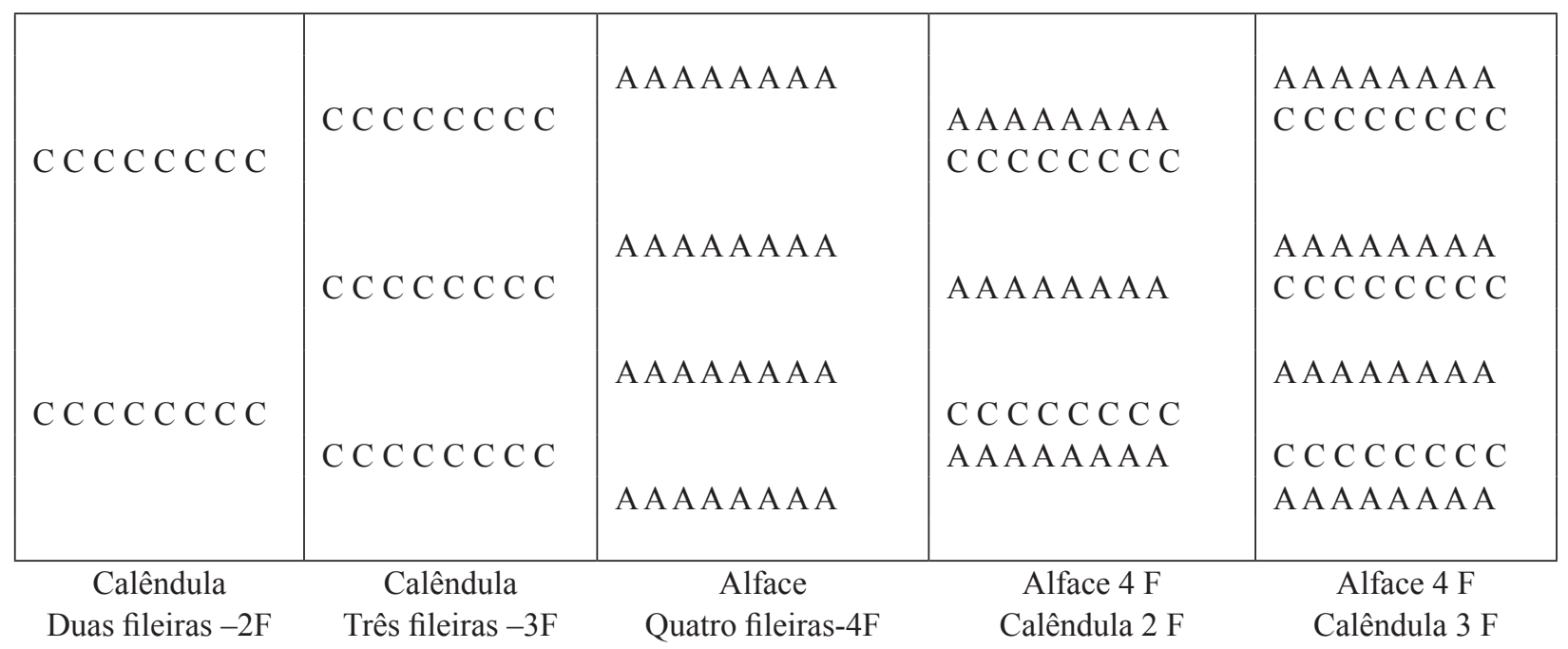

Fonte: Elaboração dos autores.

As mudas de calêndula e alface foram produzidas em casa de vegetação, coberta com plástico branco transparente e sombrite 50\%, utilizando-se bandejas de isopor contendo 128 células e preenchidas com substrato comercial Plantmax ${ }^{\circledR}$. A composição química do substrato foi de 4,7 de $\mathrm{pH}\left(\mathrm{H}_{2} \mathrm{O}\right) ; 97,82$ $\mathrm{g} \mathrm{kg}^{-1}$ de matéria orgânica; $610 \mathrm{mg} \mathrm{dm}^{-3}$ de $\mathrm{P}$ e 35,38; 69,30; 40,20; 3, 10 e 204,60 $\mathrm{cmol}_{\mathrm{c}} \mathrm{dm}^{-3}$ de K, $\mathrm{Ca}, \mathrm{Mg}, \mathrm{Al}, \mathrm{H}+\mathrm{Al}$, respectivamente e $41 \%$ de $\mathrm{V}$. 
O solo da área do experimento foi preparado mediante aração, gradagem niveladora e levantamento dos canteiros com rotoencanteirador. O transplante da calêndula e da alface, ao local definitivo, foram no mesmo dia, sendo para calêndula aos 25 dias após a semeadura, quando as mudas apresentavam cerca de $0,15 \mathrm{~m}$ de altura e para alface foi aos 34 dias após a semeadura. Nesse mesmo dia houve a semeadura direta do rabanete, efetuando-se o desbaste aos 10 dias após a emergência das plantas. As irrigações foram feitas por aspersão com o intuito de manter o solo com aproximadamente $70 \%$ da capacidade de campo, o que induziu a turnos de rega a cada dois dias. $\mathrm{O}$ controle das plantas infestantes foi feito com auxílio de enxadas nas entrelinhas e por arranquio manual dentro das linhas. Na condução do experimento não foram detectadas presenças de pragas e/ou doenças.

Durante o ciclo de cultivo da calêndula foram medidas as alturas das plantas com intervalos de oito dias, entre 20 e 108 dias após o transplante (DAT). A partir de 30 DAT, com intervalo médio de seis dias, foram colhidos todos os capítulos florais da calêndula, pela manhã, durante treze semanas consecutivas, usando como índice de colheita a abertura dos capítulos florais. Nos capítulos florais foram avaliados o número, o diâmetro e as massas fresca e seca, esta após secagem em estufa com circulação forçada de ar, a $40 \pm 2^{\circ} \mathrm{C}$, até a obtenção de massa constante.

A colheita do rabanete foi feita 40 dias após a semeadura, quando avaliaram-se o comprimento e o diâmetro, os números de raízes comerciais e não comerciais e as massas fresca e seca das raízes e da parte aérea. A colheita da alface foi aos 65 DAT, utilizando-se como índices de colheita a perda de brilho das folhas, quando avaliaram-se o diâmetro, o número e a altura de plantas comerciais e as massas frescas e secas de plantas. Na calêndula considerouse como final do ciclo de cultivo, quando havia sinais de senescência das folhas, aos 120 DAT, época em que foram colhidas todas as plantas das parcelas, cortando-as rente ao solo, para obtenção das massas frescas e secas da parte aérea.
O consórcio foi avaliado utilizando a expressão da razão de área equivalente (RAE) proposta por Caetano; Ferreira e Araújo (1999), a saber: $\mathrm{RAE}=\mathrm{CcCs}^{-1}+\mathrm{AcAs}^{-1}$ ou $\mathrm{CcCs}^{-1}+\mathrm{RcRs}^{-1}$ onde, respectivamente, $\mathrm{Cc}$, Ac e $\mathrm{Rc}=$ produções de massa fresca da calêndula, da alface e do rabanete consorciados e Cs, As e Rs = produções de massa fresca da calêndula, da alface e do rabanete solteiros. A validação do consórcio foi realizada mediante a determinação da renda bruta. Para isso, foram avaliados maços de rabanete, de vários locais de venda no varejo em Dourados-MS, e determinadas as massas frescas (média de 440,0 g) e preço pago aos produtores que foi de $\mathrm{R} \$ 0,40$ por maço. Para a alface, o preço médio pago aos produtores foi de $\mathrm{R} \$$ 0,30 por "cabeça". O preço por quilo de massa seca de capítulos florais de calêndula foi de R $\$ 20,00$ (MFRURAL, 2010). Posteriormente, efetuaramse as conversões por hectare da renda bruta, por cultivo e total.

Aos dados de altura das plantas da calêndula foram ajustadas equações de regressão, em função dos dias após o transplante, com o emprego de polinômios ortogonais. Os dados de produção foram analisados individualmente por espécie e submetidos à análise de variância, utilizandose o aplicativo computacional SAEG (RIBEIRO JÚNIOR, 2001). Quando se detectou significância pelo teste $\mathrm{F}$, as médias foram testadas por Tukey, até $5 \%$ de probabilidade (BANZATTO; KRONKA, 1989).

\section{Resultados e Discussão}

O padrão de crescimento em altura das plantas de calêndula ajustou-se ao modelo quadrático, com taxas de crescimento significativamente semelhantes, demonstrando que não houve efeito dos tratamentos e que a forma de crescimento deve ser característica da cultivar 'Bonina', que foi estudada (Figura 2). Os pontos de máximo foram alcançados aos 108 dias após o transplante, com diferença de $8,55 \mathrm{~cm}$ entre a altura das plantas do 
cultivo solteiro de calêndula com três fileiras $(53,69$ $\mathrm{cm})$ e a altura das plantas do consórcio calêndula três fileiras e rabanete quatro fileiras $(45,14$ $\mathrm{cm})$. Padrões de crescimento diferentes foram observados por Barbosa et al. (2009), em Dourados,
MS, ao avaliarem plantas de calêndula cultivadas sob diferentes doses de fósforo e de cama-de-frango semidecomposta, onde o crescimento em altura das plantas foi dependente dos tratamentos, com respostas lineares e cúbicas.

Figura 2. Altura de plantas de calêndula 'Bonina', cultivadas solteiras e consorciadas com alface e rabanete em função de dias após o transplante. C.V.(\%) = 8,8. UFGD, Dourados, 2009. (C2 = duas fileiras de calêndula; C3 = três fileiras de calêndula; $\mathrm{C} 2 \mathrm{~A} 3$ = duas fileiras de calêndula e três fileiras de alface; C2R3 = três fileiras de calêndula e quatro fileiras de rabanete; $\mathrm{C} 3 \mathrm{~A} 4$ = três fileiras de calêndula e quatro fileiras de alface; C3R4 = três fileiras de calêndula e quatro fileiras de rabanete).

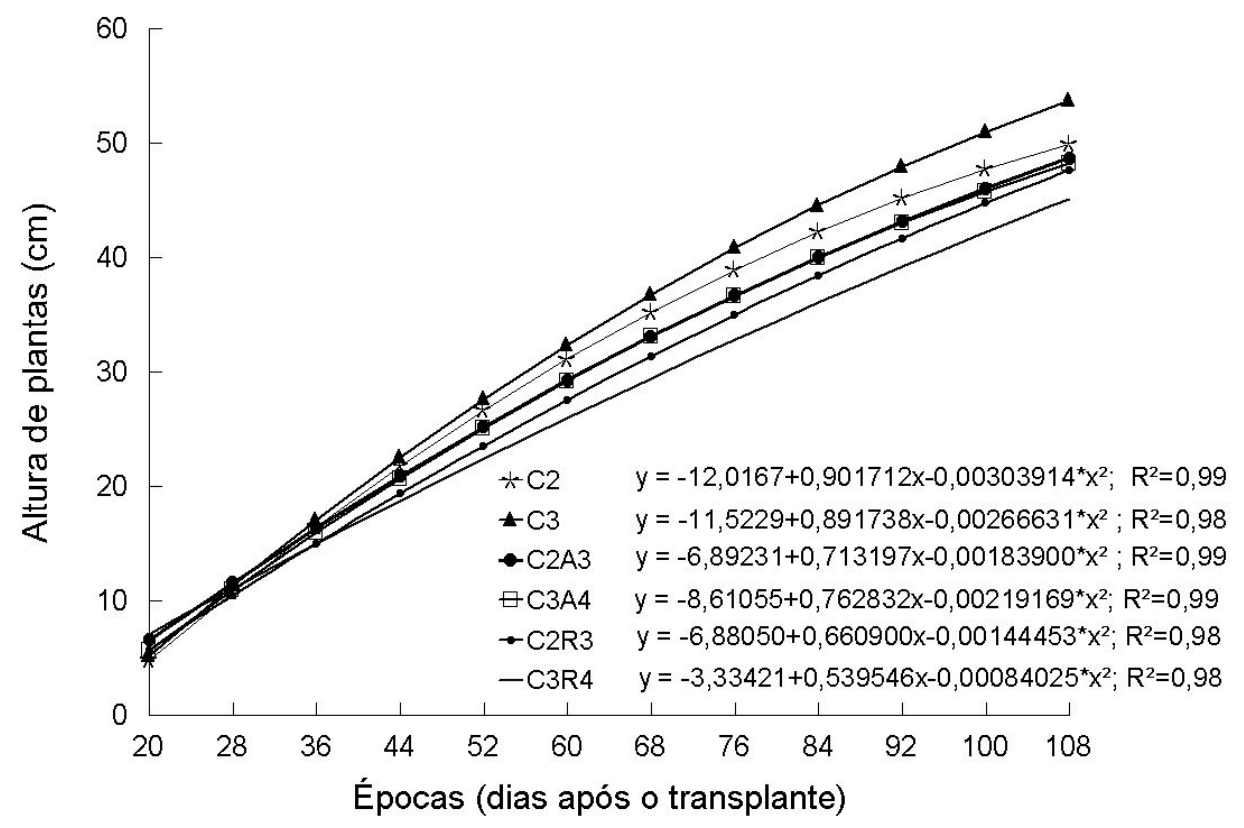

Fonte: Elaboração dos autores.

O número e as massas frescas e secas de capítulos florais da calêndula foram influenciados significativamente pela interação entre sistemas de cultivo e número de fileiras no canteiro (Tabela 1). Diferenças significativas foram observadas dentro do sistema solteiro onde o cultivo com três fileiras de plantas induziu aumentos de $3.046,6 \mathrm{~kg}$ $\mathrm{ha}^{-1}$ de massa fresca, 373,94 $\mathrm{kg} \mathrm{ha}^{-1}$ de massa seca e 1.578,01 mil ha-1 de capítulos florais em relação ao cultivo solteiro com duas fileiras. Dentro dos cultivos consorciados, os valores obtidos para o número e para as massas fresca e seca dos capítulos florais da calêndula foram semelhantes estatisticamente. Esses resultados são coerentes com o exposto por Taiz e Zeiger (2009), de que a maximização da produção depende da densidade, do sistema de produção empregado e da distribuição espacial adequada de plantas na área. 
Tabela 1. Número de capítulos florais (NCF) e massas frescas (MFCF) e secas (MSCF) de capítulos florais da calêndula 'Bonina' aos 120 dias após o transplante, cultivada solteira e consorciada, com duas e três fileiras de plantas no canteiro. UFGD, Dourados, 2009.

\begin{tabular}{|c|c|c|c|c|c|}
\hline \multicolumn{3}{|c|}{ Fatores em estudo } & \multirow{2}{*}{$\begin{array}{c}\text { NCF } \\
\left(1000 \text { ha }^{-1}\right)\end{array}$} & \multirow{2}{*}{$\begin{array}{c}\text { MFCF } \\
\left(\mathrm{kg} \mathrm{ha}^{-1}\right)\end{array}$} & \multirow{2}{*}{$\begin{array}{c}\text { MSCF } \\
\left(\mathrm{kg} \mathrm{ha}^{-1}\right)\end{array}$} \\
\hline Cultivo & Espécie & Fileiras & & & \\
\hline \multirow{2}{*}{ Solteiro } & Calêndula & 2 & $2.672,74 \mathrm{~b}$ & $4.531,42 \mathrm{~b}$ & $554,15 \mathrm{~b}$ \\
\hline & Calêndula & 3 & $4.250,75 \mathrm{a}$ & $7.578,00 \mathrm{a}$ & $928,09 \mathrm{a}$ \\
\hline \multirow{6}{*}{ Consórcio } & Calêndula & 2 & $2.613 .63 \mathrm{a}$ & $5.786 .25 \mathrm{a}$ & $631.03 \mathrm{a}$ \\
\hline & Alface & 3 & & & \\
\hline & $\begin{array}{c}\text { Calêndula } \\
\text { Alface }\end{array}$ & $\begin{array}{l}3 \\
4\end{array}$ & $3.358,30 \mathrm{a}$ & $5.448,80 \mathrm{a}$ & $675,16 \mathrm{a}$ \\
\hline & Calêndula & $\begin{array}{l}2 \\
3\end{array}$ & $2.337,66 \mathrm{a}$ & $3.784,54 \mathrm{a}$ & $496,52 \mathrm{a}$ \\
\hline & $\begin{array}{l}\text { Calêndula } \\
\text { Rabanete }\end{array}$ & $\begin{array}{l}3 \\
4\end{array}$ & $2.025,47 \mathrm{a}$ & $3.461,16 \mathrm{a}$ & $414,78 \mathrm{a}$ \\
\hline & C.V. $(\%)$ & & 21,37 & 21,77 & 17,43 \\
\hline
\end{tabular}

Médias seguidas da mesma letra nas colunas, para cada forma de cultivo, não diferem estatisticamente pelo teste de Tukey, até 5\% de probabilidade.

Fonte: Elaboração dos autores.

O diâmetro dos capítulos florais da calêndula foi influenciado significativamente pela forma de cultivo sendo maior nos produzidos pelas plantas cultivadas solteiras e nas consorciadas com alface, superando em 0,23 e $0,22 \mathrm{~cm}$ aos capítulos das plantas cultivadas consorciadas com rabanete (Tabela 2). As massas frescas e secas da parte aérea das plantas cultivadas solteiras foram significativamente maiores que as das cultivadas consorciadas, independente do número de fileiras no canteiro (Tabela 2). Esse fato está provavelmente relacionado com a manutenção da eficiência na absorção e/ou, no uso da água, dos nutrientes e do $\mathrm{CO} 2$, pois na maioria das culturas consorciadas é notada redução de produtividade (MORAES ANTUNES et al., 2008).

Tabela 2. Diâmetro de capítulos florais e massas frescas (MFPA) e secas (MSPA) da parte aérea da calêndula 'Bonina', em cultivo solteiro e consorciado, aos 120 dias após o transplante. UFGD, Dourados, 2009.

\begin{tabular}{|c|c|c|c|c|}
\hline \multicolumn{2}{|c|}{ Fatores em estudo } & \multirow{2}{*}{$\begin{array}{c}\text { Diâmetro (cm) } \\
4,76 \mathrm{a} \\
\end{array}$} & \multirow{2}{*}{$\begin{array}{c}\operatorname{MFPA}\left(\mathbf{k g ~ h a} \mathbf{~ a}^{-1}\right) \\
18.251,37 \mathrm{a} \\
\end{array}$} & \multirow{2}{*}{$\begin{array}{c}\operatorname{MSPA}\left(\mathbf{k g ~ h a} \mathbf{~ a}^{-1}\right) \\
4.909,61 \mathrm{a} \\
\end{array}$} \\
\hline Solteiro & Calêndula & & & \\
\hline \multirow{2}{*}{ Consórcio } & Calêndula Alface & $4,75 \mathrm{a}$ & $13.475,21 \mathrm{~b}$ & $3.494,83 \mathrm{~b}$ \\
\hline & Calêndula Rabanete & $4,53 \mathrm{~b}$ & $14.040,43 \mathrm{~b}$ & $3.753,27 \mathrm{~b}$ \\
\hline \multicolumn{2}{|c|}{ C.V. $(\%)$} & 3,51 & 16,22 & 18,35 \\
\hline
\end{tabular}

Médias seguidas da mesma letra nas colunas não diferem estatisticamente pelo teste de Tukey, até $5 \%$ de probabilidade.

Fonte: Elaboração dos autores.

$\mathrm{Na}$ produção de alface foram detectadas influências significativas da forma de cultivo sobre os diâmetros das "cabeças" comerciais e não comerciais e sobre a massa fresca de "cabeças" comerciais (Tabela 3). Os maiores diâmetros e a maior massa fresca de "cabeças" comerciais foram das plantas cultivadas solteiras confirmando a citação de Santos (1998) que, sob policultivo, a produção é menor. Isso porque, as interferências negativas entre espécies vegetais dizem respeito a prováveis efeitos alelopáticos ou à competição por recursos como água, nutrientes, gás carbônico e luz (VANDERMEER, 1989). 
Pelloso, I. A. O. et al.

Tabela 3. Diâmetro, número e massa fresca de "cabeças" de alface 'Verônica', comercial e não comercial, em cultivo solteiro e consorciado, com três e quatro fileiras de plantas no canteiro. UFGD, Dourados, 2009.

\begin{tabular}{|c|c|c|c|c|c|c|c|}
\hline \multirow{3}{*}{\multicolumn{2}{|c|}{ Fatores em estudo }} & \multicolumn{6}{|c|}{ Produção de "cabeças" de alface } \\
\hline & & \multicolumn{3}{|c|}{ Comercial } & \multicolumn{3}{|c|}{ Não-comercial } \\
\hline & & $\begin{array}{l}\text { Diâm. } \\
\text { (cm) }\end{array}$ & $\begin{array}{l}\text { Número } \\
\left(\text { mil ha }^{-1}\right)\end{array}$ & $\begin{array}{c}\text { Massa fresca } \\
\left(\mathrm{kg} \mathrm{ha}^{-1}\right)\end{array}$ & $\begin{array}{l}\text { Diâm. } \\
\text { (cm) }\end{array}$ & $\begin{array}{l}\text { Número } \\
\left(\text { mil ha }^{-1}\right)\end{array}$ & $\begin{array}{c}\text { Massa fresca } \\
\left(\mathrm{kg} \mathrm{ha}^{-1}\right)\end{array}$ \\
\hline \multicolumn{8}{|c|}{ Forma de cultivo } \\
\hline Solteiro & Alface & $24,39 \mathrm{a}$ & $58,69 \mathrm{a}$ & $7.783,33 \mathrm{a}$ & $18,10 \mathrm{a}$ & $22,89 \mathrm{a}$ & $1.138,69 \mathrm{a}$ \\
\hline Consórcio & $\begin{array}{c}\text { Alface } \\
\text { Calêndula }\end{array}$ & $21,15 b$ & $47,45 \mathrm{a}$ & $4.715,71 \mathrm{~b}$ & $15,81 \mathrm{~b}$ & 34,13 a & $1.078,99 \mathrm{a}$ \\
\hline \multicolumn{8}{|c|}{ Arranjo de plantas } \\
\hline $3 \mathrm{li}$ & & $23,14 \mathrm{a}$ & $49,47 \mathrm{a}$ & $5.719,98 \mathrm{a}$ & $18,11 \mathrm{a}$ & $20,45 \mathrm{a}$ & $1.072,59 \mathrm{a}$ \\
\hline $4 \mathrm{li}$ & & 22,49 a & $55,87 \mathrm{a}$ & $6.661,38 \mathrm{a}$ & 16,06 a & $34,78 \mathrm{a}$ & $1.137,03 \mathrm{a}$ \\
\hline C.V & $(\%)$ & 15,33 & 25,02 & 41,12 & 10,93 & 63,77 & 45,55 \\
\hline
\end{tabular}

Médias seguidas da mesma letra nas colunas, para cada forma de cultivo, não diferem estatisticamente pelo teste de Tukey até $5 \%$ de probabilidade.

Fonte: Elaboração dos autores.

Em relação ao rabanete, houve influência significativa dos fatores isolados sobre a massa fresca (Tabela 4). As maiores produções foram obtidas no cultivo consorciado, que superou em $15,71 \%\left(504,51 \mathrm{~kg} \mathrm{ha}^{-1}\right)$ ao cultivo solteiro e no cultivo com quatro fileiras que superou em $13,67 \%$ $\left(437,73 \mathrm{~kg} \mathrm{ha}^{-1}\right)$ ao cultivo com três fileiras. Esses resultados sobre o consórcio provavelmente foram obtidos pela complementação das culturas na utilização da água, dos nutrientes, do solo, da luz e na ocupação do espaço físico, uma interação interespecífica, implicando em vantagens para as plantas do rabanete. Isso porque, a produtividade das culturas em consórcio pode ser influenciada pelo período de convivência entre as espécies, devido a diferenças dos ciclos de produção, ocasionando competições interespecíficas no desenvolvimento das plantas.

As razões de área equivalente (RAEs) para os consórcios foram todos maiores que 1,00 e por isso consideradas efetivas, mas, as RAEs referentes aos consórcios da calêndula duas fileiras e alface ou rabanete três fileiras de plantas por canteiro foram maiores que as RAEs relacionadas com calêndula três fileiras e alface ou rabanete com quatro fileiras (Tabela 5). Comparativamente, a melhor RAE foi de 2,38 para o consórcio calêndula duas fileiras e rabanete três fileiras. Esses resultados mostram que os arranjos espaciais são importantes fatores de manejo que podem ser manipulados para melhorar o uso de recursos e a eficiência da prática do consórcio em hortaliças (HEREDIA ZÁRATE et al., 2006a).

Pelos valores obtidos para as RAE e para as rendas brutas, observou-se que o consórcio com maior RAE, do tratamento calêndula duas fileiras e rabanete com três fileiras, não induziu a maior renda bruta para o agricultor. O tratamento onde se fez o consórcio da calêndula com duas fileiras e alface com três fileiras, que teve a segunda maior RAE, foi a que induziu a maior renda bruta. Esses resultados concordam com Silva (1983) e Sullivan (1998), citados por Heredia Zárate et al. (2007), quando citam que o aumento da produtividade é uma das razões mais importantes para se cultivar duas ou mais culturas no sistema de consorciação, porque permite melhor aproveitamento da terra e de outros recursos disponíveis, resultando em maior rendimento econômico. 
Tabela 4. Diâmetro médio, massa fresca e número de raízes comerciais e não comerciais de plantas de rabanete 'Crimson Vip-R', cultivadas solteiras e consorciadas com calêndula 'Bonina', com de três e quatro fileiras de plantas no canteiro. UFGD, 2009.

\begin{tabular}{|c|c|c|c|c|c|}
\hline \multicolumn{2}{|c|}{ Fatores em estudo } & \multicolumn{2}{|c|}{ Comercial } & \multicolumn{2}{|c|}{ Não-comercial } \\
\hline Forma de $\mathrm{c}$ & & $\begin{array}{c}\text { Massa fresca } \\
\left(\mathrm{kg} \mathrm{ha}^{-1}\right)\end{array}$ & $\begin{array}{l}\text { Número } \\
\left(\text { mil ha }^{-1}\right)\end{array}$ & $\begin{array}{c}\text { Massa fresca } \\
\left(\mathrm{kg} \mathrm{ha}^{-1}\right)\end{array}$ & $\begin{array}{l}\text { Número } \\
\left(\text { mil ha }^{-1}\right)\end{array}$ \\
\hline Solteiro & Rabanete & $3.197,74 \mathrm{~b}$ & $202,99 \mathrm{a}$ & $2.531,41 \mathrm{a}$ & $110,86 \mathrm{a}$ \\
\hline Consórcio & Rabanete Calêndula & $3.700,25 \mathrm{a}$ & $200,63 \mathrm{a}$ & $2.156,71 \mathrm{a}$ & $78,81 \mathrm{a}$ \\
\hline \multicolumn{6}{|c|}{ Arranjo de plantas } \\
\hline & linhas & $3.202,77 \mathrm{~b}$ & $193,93 \mathrm{a}$ & $2.610,22 \mathrm{a}$ & $111,00 \mathrm{a}$ \\
\hline & linhas & $3.640,50 \mathrm{a}$ & $207,94 \mathrm{a}$ & $2.137,04 \mathrm{a}$ & $82,26 \mathrm{a}$ \\
\hline & V. $(\%)$ & 34,68 & 31,57 & 26,65 & 35,43 \\
\hline
\end{tabular}

Médias seguidas da mesma letra nas colunas, para cada forma de cultivo, não diferem estatisticamente pelo teste de Tukey até 5\% de probabilidade.

Fonte: Elaboração dos autores.

Tabela 5. Renda bruta da calêndula 'Bonina', em cultivo solteiro e consorciado com alface 'Verônica' e rabanete 'Crimson Vip-R'. Dourados, UFGD, 2009.

\begin{tabular}{|c|c|c|c|c|c|c|c|c|}
\hline \multicolumn{3}{|c|}{ Fatores em estudo } & \multicolumn{3}{|c|}{ Unidade no varejo } & \multirow[t]{2}{*}{ RAE } & \multicolumn{2}{|c|}{ Renda Bruta (R\$) $^{1}$} \\
\hline Cultivo & Espécie & Fileiras & $\begin{array}{c}\text { Inflorescência } \\
\left(\mathrm{kg} \mathrm{ha}^{-1}\right)\end{array}$ & $\begin{array}{l}\text { "Cabeça" } \\
(\text { Mil ha-1) }\end{array}$ & $\begin{array}{c}\text { Maços } \\
\left(\text { Mil ha }^{-1}\right)\end{array}$ & & $\begin{array}{c}\text { Por } \\
\text { cultivo }\end{array}$ & Total \\
\hline \multirow{6}{*}{ Solteiro } & Calêndula & 2 & 554,15 & & & 1,00 & $11.083,00$ & $11.083,00$ \\
\hline & & 3 & 928,09 & & & 1,00 & $18.561,80$ & $18.561,80$ \\
\hline & Alface & 3 & & 54,11 & & 1,00 & $21.644,00$ & $21.644,00$ \\
\hline & & 4 & & 63,27 & & 1,00 & $25.308,00$ & $25.308,00$ \\
\hline & Rabanete & 3 & & & 6,34 & 1,00 & $3.170,00$ & $3.170,00$ \\
\hline & & 4 & & & 8,18 & 1,00 & $4.090,00$ & $4.090,00$ \\
\hline \multirow{8}{*}{ Consórcio } & Calêndula & 2 & 631,03 & \multirow[b]{2}{*}{49,12} & & \multirow{2}{*}{2,05} & $12.620,60$ & \multirow{2}{*}{$32.268,60$} \\
\hline & Alface & 3 & & & & & $19.648,00$ & \\
\hline & Calêndula & 3 & 675,16 & \multirow[b]{2}{*}{45,79} & & \multirow{2}{*}{1,44} & $13.503,20$ & \multirow{2}{*}{$31.819,20$} \\
\hline & Alface & 4 & & & & & $18.316,00$ & \\
\hline & Calêndula & 2 & \multirow[t]{2}{*}{496,52} & & & \multirow{2}{*}{2,38} & $9.930,40$ & \multirow{2}{*}{$14.635,40$} \\
\hline & Rabanete & 3 & & & 9,41 & & $4.705,00$ & \\
\hline & Calêndula & 3 & \multirow[t]{2}{*}{414,78} & & & \multirow{2}{*}{1,35} & $8.295,60$ & \multirow{2}{*}{$11.995,60$} \\
\hline & Rabanete & 4 & & & 7,40 & & $3.700,00$ & \\
\hline
\end{tabular}

'Preço pago no varejo em Dourados-MS: R\$ 0,40 a "cabeça” de alface, R \$ 0,50 o maço de rabanetes (440 g), R\$20,00 o quilo de capítulos florais secos de calêndula, conforme (MFRURAL, 2010).

Fonte: Elaboração dos autores.

\section{Conclusões}

Considerando a razão de área equivalente (RAE) e a renda bruta, os consórcios foram melhores que os cultivos solteiros. Para os produtores de calêndula e de alface recomenda-se o consórcio calêndula com duas fileiras e alface com três fileiras e para o produtor de rabanete, recomenda-se o consórcio calêndula com duas fileiras e rabanete com três fileiras, para que obtenham maior renda bruta.

\section{Agradecimentos}

Ao CNPq, pelas bolsas concedidas e à FUNDECT-MS, pelo apoio financeiro. 


\section{Referências}

AMIRGHOFRAN, Z.; AZADBAKHT, M.; KARIMI, M. $\mathrm{H}$. Evaluation of the immunomodulatory effects of five herbal. Journal of Ethnopharmacology, London, v. 72, n. 1-2, p. 167-172, 2000.

BANZATTO, D. A.; KRONKA, S. N. Experimentação agrícola. Jaboticabal: FUNEP, 1989.

BARBOSA, V. C.; VIEIRA, M. C.; HEREDIA ZÁRATE, N. A.; BOTEGA, S. P.; PADILHA, N. S.; PAES, C. L. Produção de biomassa de Calendula officinalis L. adubada com fósforo e cama-de-frango. Ciência $e$ Agrotecnologia, Lavras, v. 33, n. 2, p. 478-483, 2009.

BAUMANN L. S. Cosmeceutical critique: calendula. (Dermatologic Therapy). Skin \& Allergy News, New York, v. 34, n. 1, p. 17, 2003.

BEZERRA NETO, F.; ANDRADE, F. V.; NEGREIROS, M. Z.; SANTOS JÚNIOR, J. J. S. Desempenho agroeconômico do consórcio cenoura $\mathrm{x}$ alface lisa em dois sistemas de cultivo em faixas. Horticultura Brasileira, Brasília, v. 21, n. 4, p. 635-641, 2003.

CAETANO, L. C. S.; FERREIRA, J. M.; ARAÚJO, M. de. Produtividade da alface e cenoura em sistema de consorciação. Horticultura Brasileira, Brasília, v. 17, n. 2, p. 143-146, 1999.

CAMARGO, L. S. As hortaliças e seu cultivo. 3. ed. Campinas: Fundação Cargill, 1992.

CECÍLIO FILHO, A. B.; MAY, A. Produtividade das culturas de alface e rabanete em função da época de estabelecimento do consórcio. Horticultura Brasileira, Brasília, v. 20, n. 3, p. 501-504, 2002.

COSTA, C. P.; SALA, F. C. A evolução da alfacicultura brasileira. Horticultura Brasileira, Brasília, v. 23, n. 1, 2005. Verso da capa.

CRNOBARAC, J.; JA'CIMOVI'C, G.; MARINKOVI'C, B.; MIRCOV, V. D.; MRDA, J.; MILICA, B. Dynamics of pot marigold yield formation depended by varieties and row distance. Hameiul si Plantele Medicinale, ClujNapoca, v. 31, n. 1-2, p. 1-8, 2008.

CROMACK, H. T. H.; SMITH, J. M. Calendula officinalis - production potential and crop agronomy in southern England. Industrial Crops and Products, Maryland, v. 7, n. 2, p. 223-229, 1998.

ELIAS, R.; DE MÉO, M.; OLLIVIER, V. E.; LAGET, M.; BALANSARD, G.; DUMENIL, G. Antimutagenic activity of some saponins isolated from Calendula officinalis L., C. arvensis L. and Hedera helix L. Mutagenesis, Oxford, v. 5, n. 4, p. 327-331, 1990.
EL-SHAZLY, A. M.; HUSSEIN, K. T. Chemical analysis and biological activities of the essential oil of Teucrium leucocladum Boiss. (Lamiaceae). Biochemical Systematics and Ecology, Maryland, v. 32, n. 7, p. 665674, 2004.

FILGUEIRA, F. A. R. Novo manual de olericultura: agrotecnologia moderna na produção e comercialização de hortaliças. 3. ed. Viçosa: UFV, 2008.

FREITAS, K. K. C.; NEGREIROS, M. A.; BEZERRA NETO, F.; AZEVEDO, C. M. S. B.; OLIVEIRA, E. Q.; BARROS JÚNIOR, A. P. Uso de efluente e água de rio no desempenho agroeconômico de cenoura, alface e coentro em associação. Caatinga, Mossoró, v. 17, n. 2, p. 98-104, 2004.

FROMENT, M.; MASTEBROEK, D.; GORP, K. $A$ growers manual for Calendula officinalis L. 2005. Disponível em: <http://www.mbzerotill.com/files/ Calendula\%20Growers\%20 Manual.pdf $\$$. Acesso em: 10 dez. 2011.

GIL, B. A.; CASTILlO, R. M.; ROQUE, C. G.; FERNÁNDEZ, D. F. Extracto acuoso de Calendula officinalis. Estudio preliminar de sus propiedades. Revista Cubana Plantas Medicinales, La habana, v. 5, n. 1, p. 30-31, 2000.

GOMES, H. E.; VIEIRA, M. C.; HEREDIA, Z. N. A. Densidade e arranjo de plantas na produção de Calendula officinalis L. Revista Brasileira de Plantas Medicinais, Botucatu, v. 9, n. 3, p. 117-123, 2007.

GRUENWALD, J.; BRENDLER, T.; JAENICKE, C. PDR for Herbal Medicines - the information standard for complementary medicines. 2. ed. New Jersey: Thomson Medical Economics at Montvale, 2000, 858 p.

HELALY, F. M.; AHMED, A. A.; EL-GHAFFAR, M. A. A. Natural rubber base matrix containing Calendula officinalis plant as a source of molluscicidal saponin. Journal of Controlled Release, Maryland, v. 57, n. 1, p. 1-7, 1999.

HEREDIA ZÁRATE, N. A.; VIEIRA, M. C.; GIULIANI, A. R.; HELMICH, M.; CHIQUITO, E. G.; AMADORI, A. H. Taro 'Chinês' em cultivo solteiro e consorciado com cenoura Brasília e alface quatro estações. Horticultura Brasileira, Brasília, v. 24, n. 3, p. 324-328, 2006a.

HEREDIA ZÁRATE, N. A.; VIEIRA, M. C.; GRACIANO, J. D.; GASSI, R. P.; ONO, F. B.; AMADORI, A. H. Produção de cebolinha, solteira e consorciada com rúcula, com e sem cobertura do solo com cama-de-frango. Semina: Ciências Agrárias, Londrina, v. 27, n. 4, p. 505-514, 2006b. 
HEREDIA ZÁRATE, N. A.; VIEIRA, M. C.; HELMICH, M.; CHIQUITO, E. G.; QUEVEDO, L. F; SOARES MENDES, E. Produção e renda bruta da cultura do taro, em cultivo solteiro e consorciado com as culturas da salsa e do coentro. Acta Scientiarum: Agronomy, Maringá, v. 29, n. 1, p. 83-89, 2007.

HSIEH, P. C.; MAU, J. L.; HUANG, S. H. Antimicrobial effects of various combinations of plant extracts. Food Microbiology, Edinburg, v. 18, n. 1, p. 35-43, 2001.

KALVATCHEV, Z.; WALDER, R.; GARZARO, D. Anti-HIV activity of extracts from Calendula officinalis flowers. Biomedical Pharmacotheraphy, v. 51, n. 4, p. 176-180, 1997.

LUZ, L. A.; FERRADA, C. R.; GOVIN, E. S. Instrutivo técnico de Calendula officinalis. Revista Cubana de Plantas Medicinales, La Havana, v. 1, n. 1, p. 23-27, 2001.

MARTINS, E. R.; CASTRO, D. M.; CASTELLANI, D. C.; DIAS, J. E. Plantas medicinais. Viçosa: UFV, 2000.

MFRURAL. Ervas medicinais: produtos naturais no atacado. Disponível em: <www.mfrural.com.br/ detalhes. asp $x$ cdp $=34479 \&$ nmoca $=$ ERVAS-MEDICINAIS PRODUTOS-NATURAIS-NO-ATACADO>. Acesso em: 15 fev. 2010 .

MINAMI, K.; TESSARIOLI NETTO, J. Cultura de rabanete. Piracicaba: ESALQ/Departamento de Horticultura, 1994.

Rabanete: cultura rápida, para temperaturas amenas e solos areno-argiloso. Piracicaba: ESALQ, 1997.

MORAES ANTUNES, A.; VIEIRA, M. C.; HEREDIA ZÁRATE, N. A.; TEIXEIRA, I. R.; RODRIGUES, E. T. Produção da capuchinha em cultivo solteiro e consorciado com os repolhos verde e roxo sob dois arranjos de plantas. Ciência e Agrotecnologia, Lavras, v. 32, n. 4, p. 1195-1202, 2008.

OLIVEIRA, E. Q.; BEZERRA NETO, F.; NEGREIROS, M. Z.; BARROS JÚNIOR, A. P. Desempenho agroeconômico do bicultivo de alface em sistema solteiro e consorciado com cenoura. Horticultura Brasileira, Brasília, v. 22, n. 4, p. 712-717, 2004.

PEREZ, M. P.; NAVAS-CORTES, J. A.; PASCUALVILlaloBOS, M. J.; CASTILlO, P. Nematicidal activity of essential oils and organic amendments from Asteraceae against root-knot nematodes. Plant Pathology, Parkview Square, v. 52, n. 2, p. 395-401, 2003.

REZNICEK, G.; ZITTERL-EGLSEER, K. Quantitative determination of the faradiol esters in marigold flowers and extracts. Scientia Pharmaceutica, Wien, v. 71, n. 2, p. 121-128, 2003.

RIBEIRO JÚNIOR, J. I. Análises estatísticas no SAEG. Viçosa, MG: UFV, 2001.

SANTOS, R. H. S. Interações interespecificas em consórcio de olerícolas. 1998. Tese (Doutorado em Fitotecnia) - Universidade Federal de Viçosa, Viçosa.

SARTÓRIO, M. L.; TRINDADE, C.; RESENDE, P.; MACHADO, J. R. Cultivo orgânico de plantas medicinais. Viçosa: Aprenda Fácil, 2000.

SULLIVAN, P. Intercropping principles and production pratices. 2003. Disponível em: <http://www.attra. org/ attra-pub/intercrop.html\#abstract $>$. Acesso em: $10 \mathrm{dez}$. 2011.

TAIZ, L.; ZEIGER, E. Fisiologia vegetal. 4. ed. Porto Alegre: Artmed Editora S.A., 2009. 848 p.

VANDERMEER, J. H. The ecology of intercropping. Cambridge: Cambridge University Press, 1989. 237 p. 
